\title{
RESEARCH TO INDUSTRY AND INDUSTRY TO RESEARCH
}

\section{E-BIOPOND ${ }^{\circledR}$ - COUPLING MICROBIAL ELEC- TROCHEMICAL TECHNOLOGIES TO RACEWAY PONDS TO RECOVER ADDED VALUE FROM BIO- WASTE LECHATES}

The increasing interest for energy-positive and carbon-negative waste treatment processes has led to investigate hybrid biological treatment, using photosynthetic microorganisms (PM) cultivation. In these systems, an equilibrium between heterotrophic aerobes and PM is maintained: the aerobic oxidation of organic load is sustained by photosynthetic dissolved oxygen (DO) and nutrients uptake by PM simultaneously leads to remove soluble minerals. Depending on the type of lechate, large amounts of $K, N$, and $P$ are usually present, together with trace elements (B, Cu, $\mathrm{Zn}, \mathrm{Mo}, \mathrm{Fe}, \mathrm{Co}$ and $\mathrm{Mn})$, required for the growth of PM. In these systems, mechanical aeration to stimulate organic carbon oxidation could be avoided (Molinuevo-Salces et al., 2010). Besides, the obtained PM-rich sludge can be a source of added-value hydrolyzates (e.g. bio-fertilizers, bio-stimulants and plant growth promoters) (Acién et al., 2016) or molecules - e.g. natural dyes, anti-oxidants, bio-polymers, carotenoids etc. (Ledda et al., 2016).

One major concern of such approach (especially for organic-rich leachates) is the fragile equilibrium between PM and heterotrophs and the low quality of the obtained PM biomass (Acién et al., 2016). Especially for the treatment of organic-rich streams, such as animal slurries, agro-food industry wastewater and digestate from anaerobic digestion, the presence of easily bio-available organic carbon at high concentrations (soluble-COD $>1 \mathrm{~g} / \mathrm{L}$ ) favor heterotrophic bacteria growth over PM, easily driving the system to anaerobic conditions, where PM are generally inhibited (Olguín, 2012). Suspended recalcitrant organic compounds, also, tend to increase water turbidity and limit light penetration into the culture. Contamination by pathogenic bacteria present in the leachates can also limit PM growth and contribute in lowering process efficiency. Finally, excess of ammonium and other inorganic compounds can have direct inhibiting effects on PM growth rate (Ledda et al., 2016).

Here, we propose the e-BioPond ${ }^{\circledR}$ concept, based on integrating microbial electrochemical technologies to regular raceways-like ponds. This concept was developed at the e-BioCenter - University of Milan, Italy and an explorative experiment was recently published (Colombo et al., 2017). The e-BioPond ${ }^{\circledR}$ uses the electrochemical gradients generated by special microbial electrochemical pipes (MEP), to recover nutrients and oxidize organic carbon by anaerobic electroactive microbes (see Figure 1). The electrochemical system allows maximizing organic carbon ox- idation to $\mathrm{CO}_{2} / \mathrm{HCO}_{3}$ at the anode, while reducing the oxygen produced by photosynthesis in the separated cathodic chamber. Simultaneously, inorganic carbon and dissolved nutrients are allowed to diffuse through the separator to the cathodic chamber, where PM utilize them as growth medium. The MEP physically separates (by porous materials) PM from the heterotrophic microflora, while guaranteeing strong electron acceptors to anaerobic oxidizers trough the electrochemical system. This would allow obtaining high-quality PM biomass and higher process stability, as compared to state-of-the-art technology.

The system, firstly tested at labscale with a culture of Arthrospira Maxima. The system was fed in semi-continuous mode by pre-decanted swine slurries (3-5 g sCOD/L) to the anodic chamber. The hydraulic retention time in the anodic chamber was around 5 days, to obtain high COD removal rates $\left(95 \%, 0.65 \mathrm{gsCOD} \mathrm{L}^{-1} \mathrm{~d}^{-1}\right)$. Considering the overal volume of the raceway pond at demonstration scale, these figures correspond to around $7.1 \mathrm{~g}_{\mathrm{scoD}} \mathrm{m}^{-3} \mathrm{~d}^{-1}$.

At the cathode, photosynthetic DO (15-18 ppm) sustained MEP operation (electrical power densities $4 \mathrm{~W} / \mathrm{m}^{2}$ ) with considerably high coulombic efficiencies (30-50\%). This improves mineralization rates and liberates mineral

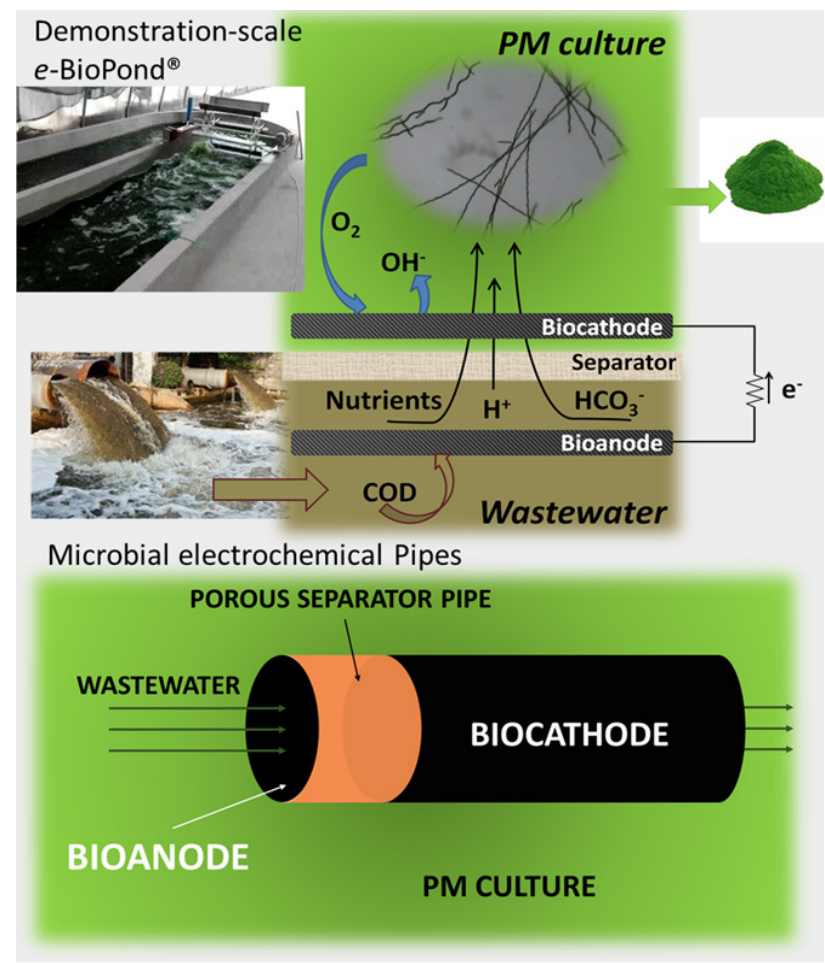

FIGURE 1: e-Biopond demonstration scale facility. 
forms of carbon and nutrients in the anodic solution. Ammonium are oxydized by different mechanisms (either anodic or microaerophilic at the interface oft he porous separator). Bicarbonate, nitrate and nitrite, as well as ionic forms of other nutrients tend to diffuse to the cathodic chamber through the porous separator. Recovery yields from anodic to cathodic compartments were measured in the range $30-70 \%$, depending on the element. Spirulina growth was regular and at a rate of around $40 \mathrm{mgTSS} \mathrm{L}^{-1} \mathrm{~d}^{-1}$ (Colombo et al., 2017), similarly to control cultures fed with standard culture medium. Another effect of the electrochemical system is the increase of $\mathrm{pH}$ in the cathodic compartment, due to incomplete $\mathrm{O}_{2}$ reduction reaction towards an accumulation of hydroxyl ions. In the case of alkalophilic PM cultures (e.g. Spirulina), this is a particular advantage for maintaining harch conditions for pathogenic microbes and in general to keep the monoculture stable.

From June 2018, the e-BioPond ${ }^{\circledR}$ system is being tested in a prototype at a demonstration-scale (raceway pond area of $26 \mathrm{~m}^{2}$ and volume of 3-5 $\mathrm{m}^{3}$ ), in collaboration with the companies Algaria srl and FCTechnics (EU-H2020 Neptune accelerator project). This plant is located in a greenhouse in proximity of a biogas-production plant and the co-generation unit provides heat to the e-BioPond unit. The raceway pond is maintained at around $28^{\circ} \mathrm{C}$ by underfloor heating exchangers. Table 1 describes the main process

TABLE 1: Main characteristics and performances of the e-BioPond ${ }^{\circledR}$ system at demonstration scale.

\begin{tabular}{|c|c|c|}
\hline & Scale & Demonstration \\
\hline Photobioreactor volume & $\mathrm{L}$ & $3000-5000$ \\
\hline HRT in anodic compartment & $d$ & 5 \\
\hline Organic concentration & gsCOD/L & 3 \\
\hline Organic loading rate & $\mathrm{g} \mathrm{sCOD} / \mathrm{m}^{3} \mathrm{pr} / \mathrm{d}$ & 7.5 \\
\hline Volumetric loading rate & $\mathrm{L} / \mathrm{m}^{3} \mathrm{pr} / \mathrm{d}$ & 2.5 \\
\hline Removal rate & $\mathrm{g} \mathrm{sCOD} / \mathrm{m}^{3} \mathrm{pr} / \mathrm{d}$ & 7.1 \\
\hline sCOD removal efficiency & & $95 \%$ \\
\hline Influent volumein batch & $\mathrm{L} / \mathrm{d}$ & 28.8 \\
\hline
\end{tabular}

parameters used in the first tests.

From the obtained biomass, Algaria srl is now extracting phycocyanin, a protein backbone to which linear tetrapyrrole chromophores are covalently bound to cys-teine residues via thioether bonds. Phycocianin has characteristic blue color, absorbing orange and red light (around $620 \mathrm{~nm}$ ) and is used for its commercial value as natural colorant in nutraceutical, cosmetic, and pharmaceutical indus-tries. Spirulina biomass obtained by the e-BioPond ${ }^{\circledR}$ concept is also under study, for its use as protein-rich feed supplement for fisheries, poultry and pigs.

Further info and contacts can be found at the website: https://sites.unimi.it/e-biocenter.

Andrea Schievano ${ }^{1, *}$, Bruno Rizzi ${ }^{1}$, Andrea Goglio ${ }^{1}$, Giovanni Rusconi Clerici ${ }^{1}$, Rosaria Tizzani ${ }^{1}$, Matteo Tucci ${ }^{1}$, Matteo Broggi ${ }^{2}$, Matteo Lucchini ${ }^{2}$ and Antonino Idà ${ }^{2}$

${ }^{1}$ e-BioCenter - ESP, University of Milano (Italy)

${ }^{2}$ Algaria srl, Milano (Italy)

*email: andrea.schievano@unimi.it

\section{REFERENCES}

Acién, F.G., Gómez-Serrano, C., Morales-Amaral, M.M., Fernández-Sevilla, J.M., Molina-Grima, E., 2016. Wastewater treatment using microalgae: how realistic a contribution might it be to significant urban wastewater treatment? Appl. Microbiol. Biotechnol. 100, 9013-9022. doi:10.1007/s00253-016-7835-7

Colombo, A., Marzorati, S., Lucchini, G., Cristiani, P., Pant, D., Schievano, A., 2017. Assisting cultivation of photosynthetic microorganisms by microbial fuel cells to enhance nutrients recovery from wastewater. Bioresour. Technol. 273, 240-248. doi:10.1016/j. biortech.2017.03.038

Ledda, C., Schievano, A., Scaglia, B., Rossoni, M., Acién Fernández, F.G., Adani, F., 2016. Integration of microalgae production with anaerobic digestion of dairy cattle manure: An overall mass and energy balance of the process. J. Clean. Prod. 112, 103-112. doi:10.1016/j.jclepro.2015.07.151

Molinuevo-Salces, B., García-González, M.C., González-Fernández, C., 2010. Performance comparison of two photobioreactors configurations (open and closed to the atmosphere) treating anaerobically degraded swine slurry. Bioresour. Technol. 101, 5144-5149. doi:10.1016/j.biortech.2010.02.006

Olguín, E.J., 2012. Dual purpose microalgae-bacteria-based systems that treat wastewater and produce biodiesel and chemical products within a Biorefinery. Biotechnol. Adv. 30, 1031-1046. doi:10.1016/j. biotechadv.2012.05.001 